\title{
Guidelines for Community-Based HIV/AIDS Stigma Reduction Intervention in a Rural Community
}

\author{
Penehafo Angula1, Busisiwe P. Ncama ${ }^{2}$ \\ ${ }^{1}$ University of Namibia [UNAM], Windhoek, Namibia \\ ${ }^{2}$ University of KwaZulu-Natal [UKZN], Durban, South Africa \\ Email: pangula@unam.na
}

Received 3 February 2016; accepted 22 March 2016; published 25 March 2016

Copyright (C) 2016 by authors and Scientific Research Publishing Inc.

This work is licensed under the Creative Commons Attribution International License (CC BY). http://creativecommons.org/licenses/by/4.0/

\section{(c) (i) 0pen Access}

\section{Abstract}

Research encourages evidence-based guidelines for practice. This paper describes the guidelines for HIV/AIDS stigma reduction in the community. These guidelines were developed by the authors based on findings of the study which was conducted to develop and evaluate HIV/AIDS stigma reduction intervention in a rural Namibian community. The developed intervention consisted of three strategies which are recommended as baseline for these guidelines. The three strategies were: education, community involvement and contacts with infected and affected groups that were implemented in this study. These strategies were implemented among the people living with HIV/AIDS (PLWHA), their families and community members from the intervention group. The post-intervention results showed significant differences on stigma reduction between the intervention and control groups, therefore these strategies were recommended for future use. Furthermore, the study found that a combination of strategies was more effective than using a single approach. Another strategy that was absent in this study but was recommended in these guidelines for future stigma reduction was: counselling approach, which could be used to address internal stigma. This paper therefore recommends that these combined strategies: education, community involvement, contacts with affected and infected groups and continuous counselling, which will be named ECCC approach might be useful to reduce HIV/AIDS stigma in the community.

\section{Keywords}

Guidelines, HIV/AIDS Stigma Reduction, Rural Community, Namibia 


\section{Introduction}

Namibia has been severely affected by the HIV/AIDS pandemic, with the first case diagnosed in 1986 and its HIV prevalence rate stood at $16.9 \%$ in 2013 [1]. The Namibian rural areas are less developed than the urban areas and have lower employment opportunities which results in internal migration. People are moving to urban areas seeking jobs opportunities and better living conditions. This migratory pattern contributes to the spread of HIV as people leave their partners and spouses in the rural areas and stay away for months [2]. When they are away from their homes, some indulge in new sexual relationships and do not use any protection making them vulnerable to HIV infection [3]. It is well documented that the HIV is especially highly concentrated in blood, semen and vaginal fluids. Moreover, HIV is transmitted primarily by unprotected sexual intercourse and it is associated with promiscuous. There are several risk factors which contribute to the spread of HIV such as gender, age, other sexually transmitted infections (STIs), socio-economic and cultural conditions [4]. There is an assumption that HIV is highly contagious, as a result people often suspect that PLWHA pose a threat to the community at large. All these contribute either indirect or directly to HIV/AIDS stigma. The guidelines in this paper will address HIV/AIDS stigma which is assumable related to HIV origin and its social background.

These guidelines are based on evidence from a quasi-experimental non-equivalent control group before and after intervention design. Although randomised control trials (RCT) are considered as the "gold standard" of evidence to support the effectiveness of interventions, when they are not feasible other designs such as quasiexperimental can provide evidence-based to inform practice. The evidence from this study is complemented with information from literature on HIV/AIDS stigma reduction interventions [5] and findings from in-depth interviews, which were conducted with community and opinion leaders and PLWHA support group members from the community. Therefore, these guidelines are based on the lessons learnt and experience from the study on assessment of HIV/AIDS stigma and development of intervention in a rural Namibian community. Although they are developed for community based HIV/AIDS stigma reduction, they might be implemented in any settings.

\section{Purpose and Scope of These Guidelines}

These guidelines aim to help health service providers and facilitators to plan for stigma reduction interventions in the community based on evidence-based interventions. The focus of these guidelines is on PLWHA who are the recipients of stigma, their families and health care providers as they experience stigma of association. When education strategy is chosen to address stigma, the developed training manuals can also be used to guide training on stigma reduction.

\section{Discussion of How to Address the Three Types of Stigma}

These guidelines are developed for rural communities to address the three types of stigma: External, internal and associated stigma, which has been reported by literature and emerged from the assessments of this study. It is important to be aware of and understand these three types of stigma before planning to intervene.

\subsection{External Stigma}

External stigma refers to received and enacted stigma, which includes any experience behaviours, attitude or discrimination acts towards PLWHA [6]. The following factors can be used to assess external stigma.

- Fear of contagion through non-sexual casual contacts for example not willing to share utensils, not touching, let person eat alone, let person drink last from the cup, ask person to leave due to coughing, not want to share toilet, shake hands and eat food prepared by a person who is HIV positive.

- Verbal abuse such as name calling, singing of offensive songs, blaming, moral judgment, scolding and insulting people who are HIV positive on the basis of their status.

- Social isolation for example ending friendship and relationship, avoidance, rejection and stop visiting a person who is HIV positive.

- Workplace stigma for example fired from work, denied opportunities due to being HIV positive.

- Attitudes, for example treat PLWHA differently, disclosing their HIV status without permission, and gossiping about them.

- Household stigma such as making PLWHA to use separate blankets, left out of family discussions and deci- 
sions, stay away from visitors, not allowed to cook for family, not allowed to play with children.

- Community opinion for example to say that teachers who are HIV positive should not be allowed to teach at schools, HIV positive learners should not go to school, PLWHA should not attend community gatherings, and they should be dismissed from work upon disclosing.

\subsection{Internal Stigma}

This refers to self -stigma, as a result of HIV positive status [6] and includes these examples:

- Negative self-perception: fear of judgment and self-blaming, person feels not deserve to live, ashamed for having the disease, feeling worthless, feeling guilty by bringing trouble to family, feeling no longer a person.

\subsection{Stigma of Association}

Stigma of association refers to stigma either to families/associates or to health care providers of PLWHA [7].

- Stigma to families of PLWHA: for example called names or gossiping about the family.

- Stigma to health care providers: by saying that health care workers who work with HIV positive patients are also positive or they will bring virus to their spouses.

\section{Strategies to Consider For HIV/Aids Stigma Reduction}

These strategies: education, community involvement and contacts with infected and affected groups, were implemented during the intervention of this study as recommended by literature [5] [8]. Research has shown that combination of strategies is more effective than using a single approach. Another strategy that was absent in this study but is recommended for future stigma reduction is counselling approach which is recommended to address internal stigma. Through this strategy the PLWHA will be taught copping skills and those who need counselling services should be assisted accordingly. The Education, Community involvement, Contacts with affected and infected groups and Continuous counselling, that will be named ECCC approach is presented Figure 1.

\section{Concepts in the Combined ECCC Approach}

The four strategies in the ECCC approach are all linked to stigma reduction and should be implemented as a combination in order to obtain significant changes.

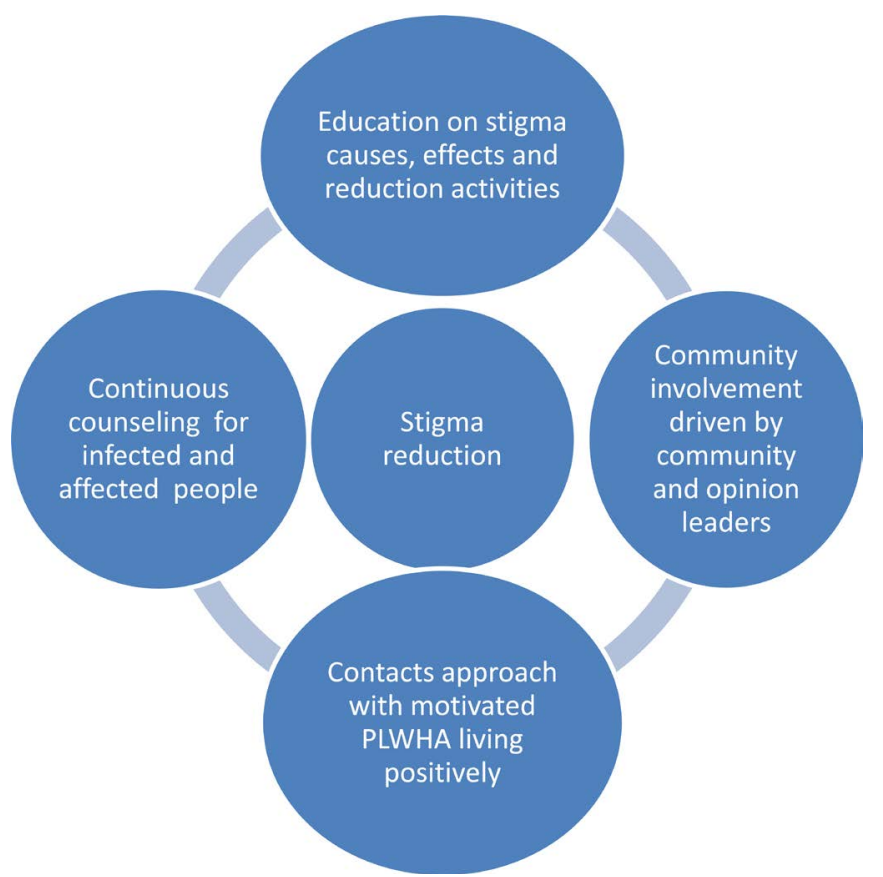

Figure 1. ECCC approach as developed by Angula and Ncama (2011). 


\subsection{Education Approach}

Education strategy should be implemented through training workshops and awareness campaigns. Two training manuals have been developed by the authors based on literature and might be used for training on stigma reduction. One manual can be used to train people living with HIV on stigma reduction the other one can be used to train community leaders, although it can also be used to train other groups such as community peer educators, youth, faith-based organization and community-based organization staff. The content of these two manuals can be used to train health professionals on stigma reduction as well. Some units' content can be used in schools to sensitize learners on stigma and its effects either on the infected or affected groups.

\subsubsection{Education Approach in Stigma Reduction Will Address the Following}

- HIV/AIDS in general for example how HIV is transmitted and how is not, to reduce fear of getting it through non-sexual casual contact.

- Educate people about stigma, its causes, and effects on the stigmatized people and teach them reduction activities.

- Education should address the most identified forms of stigma such as verbal abuse, social isolation and negative self-perception.

- Implications of reducing stigma and community benefits.

\subsubsection{The Education Approach Can Be Implemented in the Following Ways}

- Training workshops for identified and eligible trainees/participants on HIV/AIDS stigma reduction (preferable community and opinion leaders and PLWHA support group members).

- Training of the youth to become ambassadors of change and peer educators in their respective communities to influence people behavior and attitudes towards PLWHA.

- At schools teachers of Life skills subjects should teach learners about stigma, the ways of HIV transmission to increase their knowledge that will result in less fear and less stigma towards other learners who are HIV positive.

- Create a platform for students and learners to have essays competitions on HIV/AIDS stigma reduction and publish the winning essays in local newspapers.

- Use media particularly the radio to inform and educate community about HIV/AIDS stigma, causes and effects on the stigmatized as well as on the general public.

- Create a platform in the local radio stations for questions and answers on HIV/AIDS in general and on stigma in particular.

\subsection{Community Involvement: Driven by Community and Opinion Leaders}

Community involvement in any program that thrives to improve people's health or that of their beloved ones is essential. Interpersonal communications between experts (on stigma reduction) and the general public, opinion leaders, health care workers and among families of people living with HIV/AIDS and friends, are equally important as using mass media to convey the message. All available platforms such as after church services, at schools, community gatherings, sports clubs meetings and youth forums should be used to inform the people about stigma, its effects on persons who are being stigmatized and what should be done to stop or reduce it.

The Following Ways should Be Considered to Implement This Strategy

- Use community meetings to sensitize the people about HIV/AIDS stigma and how it fuels the new infections, prevents ARV adherence, prevents HIV status disclosure and affects the stigmatized groups.

- Use relevant and practical examples of stigma as it is experienced by people who are HIV positive.

- Address verbal abuse and social isolation as they are the most identified forms of external stigma in the families and community.

- Use mass media to create awareness campaign on stigma reduction particularly the radio, which is listened by majority of the rural communities who do not have access to televisions and newspapers.

- Media should address the misconceptions and myths on HIV transmission, thereby increasing the knowledge and decreasing fear of contagion from non-sexual casual contacts.

- Media should stop showing and advertising negative messages on HIV/AIDS such as "AIDS kills". Replace 
those negative advertisements with new positive messages that encourage people to stop stigmatizing others.

- Use internet services such as Face book and Twitter as well as cell phone texting to mobilize and sensitize community members on HIV/AIDS stigma and how it can be addressed.

- If it is possible let HIV/AIDS stigma also be discussed in the Parliament to get support from the government level.

- Community members should be made aware about PLWHA's rights and at the same time people who are living with HIV need to be informed about their rights and responsibilities.

- Men should take the lead in stigma reduction as they have done in the independence struggle of the country.

- Schools parents meetings should discuss the issue of stigma against learners who are on ARV so that they can be given necessary support while at schools without violating their confidentiality rights. That will also improve treatment adherence.

\subsection{Contact Approach: Motivated PLWHA Living Positively}

Contact with infected and affected groups can occurs at different levels such as physical for example being in the same room with people who are HIV positive, eating together or just being seen chatting with them without any fear of associated stigma. Verbal contact can be implemented by asking motivated PLWHA who are well counselled and living positively to give testimonials on stigma that will help people to realise the seriousness and its effects and how it blocks the HIV prevention as well as adherence to treatment. PLWHA should be trained in stigma reduction to be the ambassadors of change. People will be likely to listen and change their attitudes and behaviours if they hear stories of stigma from those who have first-hand information, persons who experienced it personally.

The Following Should Be Considered When Implementing Contacts Approach

- HIV/AIDS should become an openly spoken disease and not a whispered condition. That should be the starting point for stigma reduction which can contribute to more HIV status disclosures, but it does not mean confidentiality will be removed.

- Use audio-visual such as films e.g. "Remember Eliphas" (local Namibian film) from Ministry of Defense to show the people how community hurts the stigmatized groups. Other relevant films or pictures can be shown to sensitize the community about stigma.

- Invite well prepared, motivated and counseled PLWHA living positively to give testimonials to community members. Let them tell their stories how they experienced stigma.

- Families of people who are living with HIV should be actively involved in stigma reduction interventions.

\subsection{Continuous Counseling: For People Living with HIV/AIDS and Their Families}

Counselling is defined as a process that enables a person to sort out issues and make informed decision affecting their lives. It involves talking to a person in a way that helps to solve a problem or create a condition that makes a person to understand or improve behaviour, values or life circumstances. Research showed that HIV/AIDS is associated with emotional stresses [9] and therefore needs counselling as an appropriate means to help and support people who experience emotional problems [10] Self-stigma and emotional stresses can be addressed by:

- Providing counseling services at schools to address stigma towards teachers and learners who are HIV positive.

- Establishing more counseling services which are needed in the community to help PLWHA to overcome self-stigma and to deal with emotional problems.

- PLWHA need to be trained in coping skills with HIV/AIDS in general and with stigma in particular.

- Families of people who are HIV positive should be provided with counseling when there is a need.

\section{Enabling HIV/AIDS Stigma Reduction through Diffusion of Innovation}

A HIV/AIDS stigma reduction intervention should be implemented through the influence of innovators who can be the campaigners for the innovation (e.g. health care providers, community-based organization staff, PLWHA support group members and community leaders). These innovators will use the combination of stigma reduction strategies that include education, community involvement, contacts approach and counseling to reduce stigma 
(Figure 2). Through these strategies the innovators/adopters at different stages of Diffusion Theory (Early adopters, Majority Early Adopters, Late Adopters, and Laggards) will adopt a change in their attitudes and behavior towards the PLWHA. This change in attitude of the innovators/adopters will influence the PLWHA negative self -perception.

Influential people such as community and opinion leaders will play an important role to influence other community members to change their attitude and behaviors towards PLWHA. The community leaders and PLWHA who will be trained in stigma reduction will become the early adopters. These early adopters will mobilize the community on stigma, its causes and effects on the stigmatized and how it fuels the epidemic. If these early adopters are provided with enough support they will be able to influence the majority who will follow their example and change their attitude towards PLWHA. When the early majority adopts change, stigma will be reduced, that results in less self-stigma among those infected and affected by HIV/AIDS. The motivated PLWHA will influence others to realize that stigma is harmful, creates social inequalities in society and will be in the position to promote the importance of HIV prevention. PLWHA will use contacts approach to mobilize the community to facilitate their support.

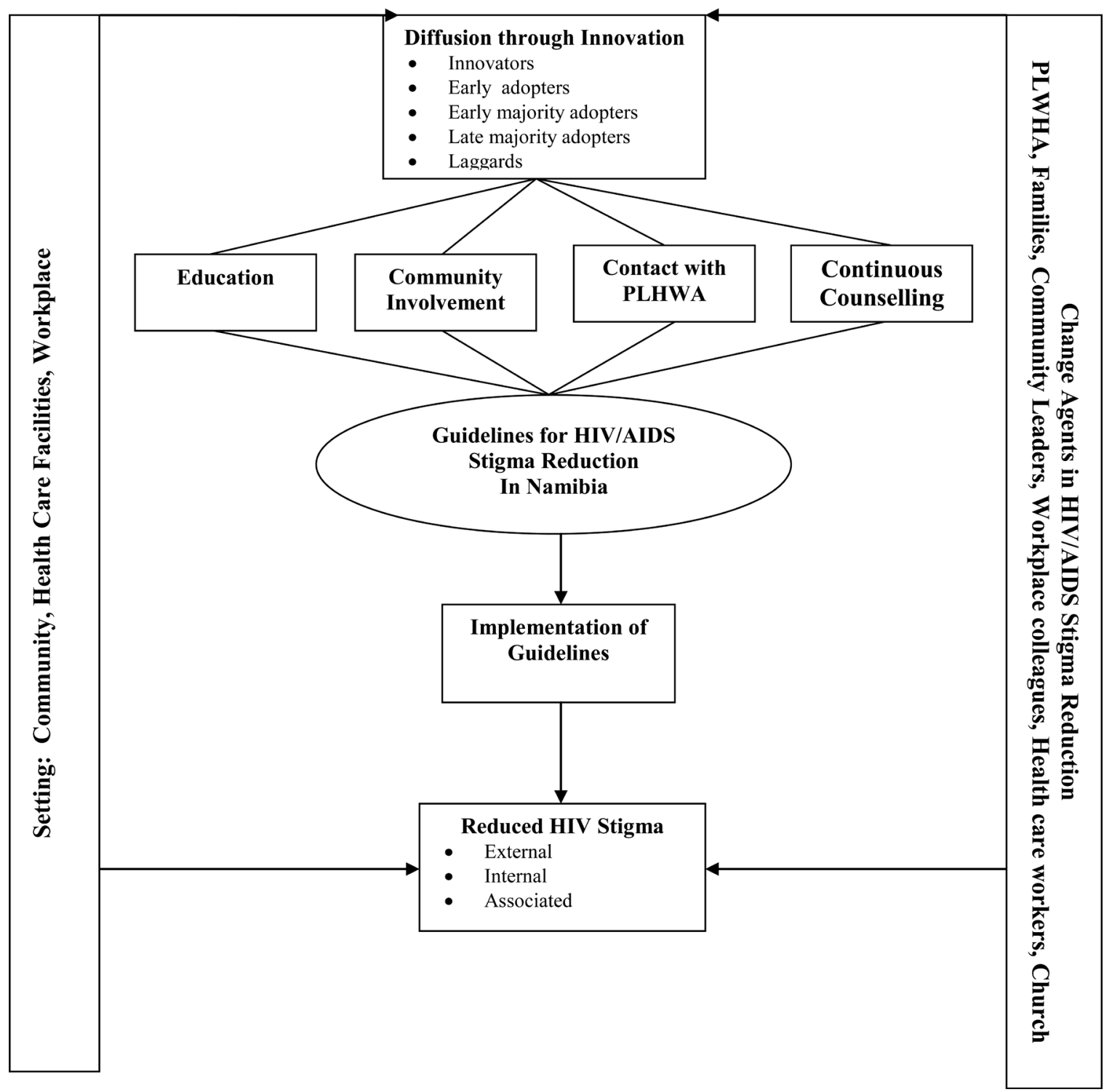

Figure 2. Flow diagram: enabling HIV/AIDS stigma reduction through the diffusion and innovations theory (Angula \& Ncama). 
The guidelines for HIV/AIDS stigma reduction in Namibia will direct campaigners and those who will be in decision making positions to plan and implement stigma reduction interventions. In the absence of health care facilities the guidelines can be implemented in community settings and can be modified to meet the needs of health care facilities. The authors believe that the implementation of these guidelines might help to reduce internal, external and associated HIV/AIDS stigma.

\section{Expected Outcomes}

It is expected that if the four combined strategies, which are education, community involvement, contacts approach and counseling are successfully implemented in the community people will become aware of HIV/AIDS stigma and how it fuels the epidemic that will result in these changes:

- Stigma will decrease in small groups first and through peer influence it will be diffused to the bigger groups, then the whole community will stop or reduce stigmatizing PLWHA and their families.

- PLWHA will report low stigma in their families and in community and will start living positively with the disease.

- If stigma decreases, more people will be willing to go for HIV testing as they will no more afraid to know their status and possible rejection due to stigma.

- If stigma decreases, people who are on ARVs will adhere to treatment and their health will improve.

- If stigma decreases, PLWHA will feel free and disclose their HIV status to their beloved ones without fear of rejection.

- The decrease of stigma will result in decreased HIV infections as people will be open about their status and start practice safer sex.

- Reduction in stigma will encourage men to accompany their partners to ANC clinics for PMTCT programs.

- As a long term goal with stigma decrease, hospitalization due to HIV related conditions will decrease as PLWHA will seek medical services on time.

- The decrease in stigma will result in reduction in the number of orphans due to HIV/AIDS as HIV positive parents will live longer and lead productive lives.

- Stigma reduction will result in a generally low mortality rate related to HIV/AIDS.

\section{Instructions for HIV/Aids Stigma Reduction}

The four combined approaches should be used to reduce stigma in the community and that can be done by applying the following instructions that are detailed below.

\subsection{Education Approach: Training (Manuals)}

- Identify communication channels that can be used to convey the message effectively: Ministry of Health, Academic Health institutions, Faith-based organizations, Ministry of Education and Mass media.

- For an example in Namibia the following organizations may benefit from using these guidelines: such as the School of Nursing and School of Public Health (at University of Namibia), Faith-based organization e.g. Catholic AIDS Action (CAA) and PLWHA support groups.

- Collaborate with other stakeholders to identify eligible people to be enrolled for training on stigma reduction.

- Budget for training materials, sessions and for human resources.

\subsection{Community Involvement}

- Identify the key person/s who will be the gatekeeper and inform community members about the innovation (stigma reduction).

- Collaborate with community representatives or key persons to obtain community entry.

- Use mass media and internet services to obtain views and opinions from the public.

- Mobilize resources needed for the intervention purposes.

\subsection{Contact Approach}

- Identify motivated PLWHA living positively who can give testimonials on stigma experiences. 
- Search and identify films/audio visual materials, which can be shown to community with a message on experiences of stigma.

- Collaborate and work closely with local PLWHA support groups and community-based organizations.

- If possible approach motivated public figures or celebrities who disclosed their HIV status to address the community to help normalize the situation.

\subsection{Continuous Counselling: PLWHA and Their Families}

- Identify lay counselors in the community who can provide continuous counseling to PLWHA and their families.

- Identify persons who are willing and eligible for training to become counselors in their respective communities.

- Collaborate with stakeholders and training institutions to arrange for training in HIV/AIDS counseling skills.

- Budget for the training of counselors.

\section{The Intended Users}

These guidelines should be used by people who wish to embark on HIV/AIDS stigma reduction using community and opinion leaders and PLWHA support group members in the community. They can be used by health professionals, community peer educators, faith-based organization and community-based organization staff when they plan stigma reduction interventions. In Namibia the following will be provided with copies of these guidelines: Ministry of Health and Social Services (MOHSS), Training institutions such as University of Namibia (UNAM) and National Health Training Canter (NHTC), Faith-based organization such as Catholic AIDS Action (CAA), PLWHA support groups such as Tonata and Opawa.

Target population: These guidelines target PLWHA, families and health care providers as well as the general public members who stigmatize others.

\section{Settings in Which the Guidelines Will Be Implemented}

HIV/AIDS is one of the biggest challenges for Namibian Health System with stigma attached to it, its impact will continue to be felt on the health service for longer unless something is done earlier than later. One of the principles of Primary Health Care (PHC) is community participation, developing these guidelines for rural community is in line with that principle. These guidelines are designed for the Community Health System to contribute to the response of HIV/AIDS challenges in general and to address stigma in particular. They are designed particularly for rural communities the reason being community and opinion leaders are more influential in rural areas than in urban. The interpersonal relationships in rural communities are more open and people have close links unlike in the urban areas where everybody minds his/her own business. It will be therefore more feasible to disseminate information on stigma reduction and implementing other strategies to influence people in the rural communities to change their attitudes towards people who are HIV positive (using interactions among communities). Although these guidelines were developed based on the Namibian rural situation they can be used anywhere if they are regarded suitable for that context.

\section{Change Agents of These Guidelines}

1) PLWHA: they should be motivated to be trained as change agents who influence other people's attitudes and behaviors towards them. They should be motivated to be able to give testimonials that will convince community members to reduce or stop stigma.

2) Families: families of PLWHA should be supported and given enough information on caring for their sick relatives who are HIV positive, how to reduce stigma in households and to support them psychologically. They should be counseled when the need arises so that they can cope and accept their family members who are HIV positive. If the family members are supported and motivated on stigma reduction they could influence change among relatives, in their neighborhood and later on in the community.

3) Community Leaders: they should be motivated so that they can play an important role to influence their subordinates on stigma reduction. The eligible community and opinion leaders should be trained in stigma reduction to mobilize the community at large. 
4) Health Care Workers: they have an important role to play in stigma reduction as the service providers such as provision of counselling, care and treatment to PLWHA and their families. Health care workers should be given necessary support in the form of training, skills building and resources to enable them to carry their duties successful.

\section{Essentials for the Guidelines}

The success of these guidelines will depend on the following:

- Willingness and preparedness of the community members to participate in the interventions activities.

- Availability of necessary resources to conduct trainings and run the awareness campaigns on HIV/AIDS stigma.

- Collaboration between all the stakeholders.

- Well motivated community leaders to take the lead in stigma reduction.

- Sufficient support to PLWHA who will act as change agents.

- Sufficient support to facilitators of the interventions.

- The correct timing of the intervention related activities.

\section{How These Guidelines Will Be Rolled out in Namibia}

The researcher will arrange a meeting with stakeholders such as representatives from Ministry of Health and Social Services (Namibia), School of Nursing and School of Public Health ( from University of Namibia), Faithbased organization namely Catholic AIDS Action (CAA) and Ministry of Regional \& Local Government, Housing \&Rural Development (MRLGH) to inform them about the guidelines. These will be the people who will disseminate information to their staff who will implement them. They will be provided with copies of the training manuals that should be used for training workshops.

\section{Challenges That Might Be Encountered during Implementation}

As it has been indicated under the essentials of these guidelines that their success depends on the willingness of the community as well as on the availability of resources, this might be a challenge. If stakeholders and community members are not prepared to be part of the implementation for these guidelines, that will be a challenge. Resources will be needed to conduct trainings, campaigns and counselling. If there are not enough resources either human or financial, that will also be a challenge.

\section{The Application History of the Guidelines}

The application history regarding the interventions and strategies to reduce HIV/AIDS stigma are based on the literature. According to Singupta and colleagues [11] in their Systematic Review of the HIV Interventions to reduce HIV/AIDS stigma most interventions and strategies used by several researchers are informational approaches, skill building, PLWHA testimonials and Counselling support groups. They further recommend that there is a need to develop combination of interventions that focus on stigma reduction and the use of more than one strategy to deliver the interventions [11]. Among the studies which were reviewed by Singupta and colleagues the Apinundecha study had used all four strategies (informational approaches, skill building, PLWHA testimonials and Counselling support groups) and these interventions reduced HIV/AIDS stigma significantly. The other intervention was done by Krauss (1999) with children where by one strategy of informational approach was applied. This strategy increased children's total comfort in interacting with PLWHA, post-intervention. It is due to this history that the authors of these guidelines developed a combination of four strategies (ECCC approach), which can be implemented to address all the three types of stigma.

\section{Conclusion}

The purpose of these guidelines is to assist, guide and direct service providers on what they can do to reduce stigma in the rural communities. If they are implemented appropriately, there is a greater chance that stigma will be reduced significantly. That will lead to more positive living with the disease, low HIV infections, improvement on ARV adherence, efficacy of PMTCT, low mortality rates related to HIV/AIDS, low costs on hospitalization and a productive and healthy community. 


\section{References}

[1] Ministry of Health and Social Services [MOHSS] (2014) Namibia Demographic and Health Survey 2013. MOHSS: Windhoek.

[2] Lurie, M. (2004) Migration, Sexuality and Rural Spread of HIV/AIDS South Africa. IDASA, Cape Town.

[3] Edwards, L. (2004) HIV/AIDS, Poverty and Patriarchy: A Gendered Perspective. Nara Training Centre, Windhoek.

[4] Van Dyk, A. (2012) HIV and AIDS, Education, Care and Counselling. A Multidisciplinary Approach. 5th Edition, CTP Printers, Cape Town.

[5] Apinundecha, C., Laohasiriwong, W., Cameron, M. P. and LIM, S. (2007) A Community Participation Intervention to Reduce HIV/AIDS Stigma, Nakhon Ratchasima Province, Northeast Thailand. AIDS Care, 19, 1157-1165. http://dx.doi.org/10.1080/09540120701335204

[6] Naidoo, R., J., Uys, R.L., Greeff, M., Holzemer, W.L., Makoae, L., Dlamini, P., Phetlhu, R.D., Chirwa, M. and Kohi, T. (2007) Urban and Rural Differences in HIV/AIDS Stigma in Five African Countries. African Journal of AIDS Research, 6 17-23. http://dx.doi.org/10.2989/16085900709490395

[7] Greeff, M., Uys, L.R., Holzemer, W.L., Makoae, L.N., Dlamini, P.S., Kohi, T.W., Chirwa, M.L., Naidoo, J.R. and Phetlhu, R.D. (2008) Experiences of HIV/AIDS Stigma of Persons Living with HIV/AIDS and Nurses Involved in Their Care from five African Countries. Africa Journal of Nursing and Midwifery, 10, 78-108.

[8] Heijnders, M. and Van Der Meij, S. (2006) The Fight against Stigma: An Overview of Stigma-Reduction Strategies and Interventions. Psychology, Health and Medicine, 11, 353-363. http://dx.doi.org/10.1080/13548500600595327

[9] Rao, D.T., Kekwaletswe, C., Hosek, S., Martinez, J. and Rodriguez, F. (2007) Stigma and Social Barriers to Medication Adherence with Urban Youth Living with HIV. AIDS Care, 19, 28-33. http://dx.doi.org/10.1080/09540120600652303

[10] Kaleeba, N., et al. (1997) Participatory Evaluation Counselling, Medical and Social Services of the AIDS Support Organization (TASO) in Uganda. AIDS Care, 9, 13-26. http://dx.doi.org/10.1080/09540129750125307

[11] Sengupta, S., Banks, B., Jonas, D., Miles, M.S. and Smith, G.C. (2010) HIV Interventions to Reduce HIV/AIDS Stigma: A Systematic Review. Springer Science + Business Media, LLC, Berlin.

\section{List of Abbreviations}

AIDS: Acquired Immune Deficiency Syndrome

ARVs: Antiretroviral Drugs

CAA: Catholic AIDS Action

DHS: Demographic and Health Survey

ECCC: Education, Community Involvement, Contacts, Continuous Counselling Approach

HIV: Human Immuno-Deficiency Virus

MOHSS: Ministry of Health and Social Services

MRLGH: Ministry of Regional \& Local Government, Housing \& Rural Development

NHTC: National Health Training Center

PHC: Primary Health Care

PLWHA: People Living with HIV/AIDS

PMTCT: Prevention of Mother-to-Child Transmission

RCT: Randomised Control Trials

UKZN: University of Kwazulu-Natal

UNAM: University of Namibia 